Universidad de La Sabana - Colombia - Universidad de La Sabana / Programas / Unidades Académicas

/ Facultad de Derecho y Ciencias Políticas / Anuario sobre DIH / Artículos

/ El Derecho Internacional Humanitario como fundamento y límite de la Responsabilidad de Proteger

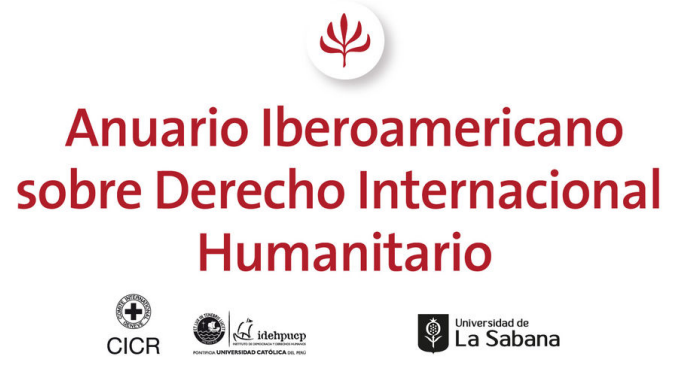

\title{
El Derecho Internacional Humanitario como fundamento y límite de la Responsabilidad de Proteger
}

\section{International Humanitarian Law as a Basis and Limit of the Responsibility to Protect}

DOI: 10.5294/aidih.2020.1.1.3 


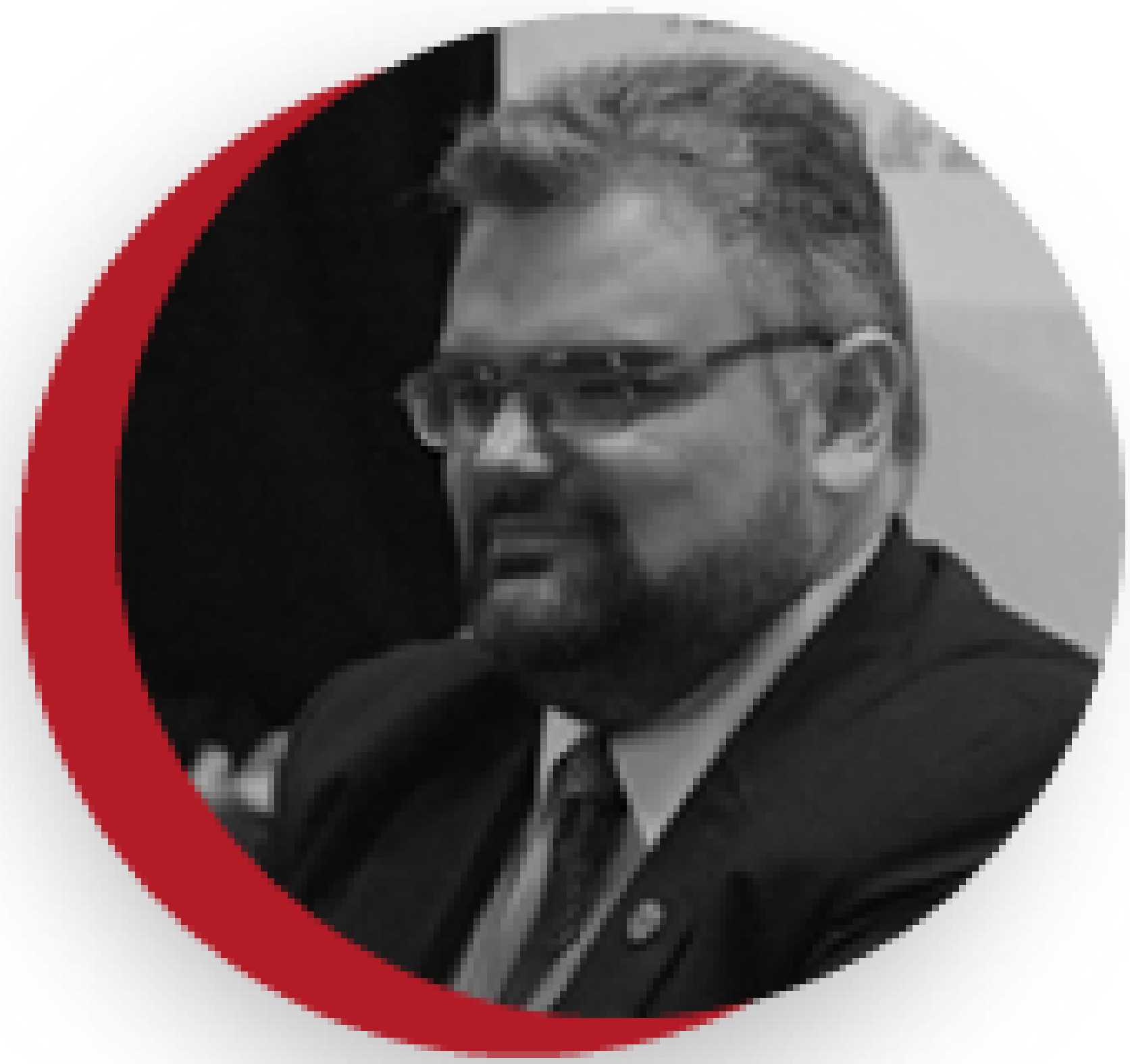

\section{Luciano Pezzano}

\section{Universidad de Ciencias Empresariales y Sociales (UCES)}

\section{Universidad Nacional de Córdoba (Becario posdoctoral CIJS-UNC/CONICET) Ipezzano@hotmail.com}

Recibido: 15 de agosto de 2019| Envío a pares: 28 de agosto de 2019| Aprobado por pares: 15 de enero de 2020| Aceptado: 15 de enero de 2020 
El artículo explora la relación entre la responsabilidad de proteger (RDP) y el derecho internacional humanitario (DIH), a partir de considerar a este último en su carácter dual de fundamento y límite de la primera. Como fundamento, en cuanto las normas humanitarias pueden dar sustento jurídico a la RDP, en lo que se refiere a parte de su contenido material -en lo que a los crímenes de guerra concierne-, a las obligaciones de los Estados respecto de la protección de las poblaciones -al menos, en el marco de los conflictos armados-, y también en cuanto a la relación entre el DIH y la activación del sistema de seguridad colectiva en virtud de la Carta de las Naciones Unidas. Como límite, en cuanto los Estados que participen de una intervención armada en ejercicio de la RDP de la comunidad internacional deben cumplir con las normas del DIH.

Palabras clave:responsabilidad de proteger; derecho internacional humanitario; protección de civiles; obligación de respetar y hacer respetar.

\begin{abstract}
The paper explores the relationship between international humanitarian law (IHL) and the Responsibility to Protect (RTOP), from a dual approach: as a part of its legal basis and as a limit. As part of the legal basis of RTOP, humanitarian norms can give it legal support, in what refers to part of its material content -i. e., war crimes-, the obligations of States in respect of the protection of populations -in an armed conflict- and also in terms of the relationship between IHL and the activation of the system of collective security under the UN Charter. As a limit, the States that participate in an armed intervention in exercise of the RTOP of the international community must comply with the rules of IHL.
\end{abstract}

Keywords: Responsibility to protect; international humanitarian law; protection of civilians; obligation to respect and to ensure respect.

\title{
Introducción
}

La responsabilidad de proteger (RDP) es uno de los conceptos más innovadores e interesantes de las relaciones internacionales del siglo XXI, y presenta no pocos desafíos para el derecho internacional.

A grandes rasgos, podemos considerar que el concepto implica que los Estados tienen la responsabilidad de proteger a su población de graves atrocidades masivas (el genocidio, los crímenes de guerra, la depuración étnica y los crímenes de lesa humanidad), y que cuando no ejerzan esa responsabilidad (por incapacidad o por falta de voluntad), la comunidad internacional, a través de las Naciones Unidas, puede adoptar medidas para ayudar a proteger a esa población, incluso, mediante el uso de la fuerza armada.

Aun en esa somera descripción podemos advertir las múltiples aristas que son susceptibles de análisis desde el derecho internacional. Aunque no podamos considerar que se trate de una norma jurídica per se,[1] no puede negarse que se trata de un concepto marco que permite vincular normas de diferentes áreas del ordenamiento jurídico internacional, como aquellas sobre el uso de la fuerza y el sistema de seguridad colectiva, el derecho internacional de los derechos humanos (DIDH), el derecho penal internacional y, lo que nos interesa aquí, el derecho internacional humanitario (DIH).

El propósito de este artículo es explorar la relación entre la RDP y el DIH, a partir de considerar a este último en su carácter dual de fundamento y límite. Como fundamento, en cuanto las normas humanitarias pueden dar sustento jurídico a la RDP, en lo que se refiere a parte de su contenido material -en lo que a los crímenes de guerra concierne-, a las obligaciones de los Estados respecto de la protección de las poblaciones -al menos, en el marco de los 
conflictos armados-, y también en cuanto a la relación entre el DIH y la activación del sistema de seguridad colectiva. Como límite, en cuanto los Estados que participen de una intervención armada en ejercicio de la RDP de la comunidad internacional deben cumplir con las normas del DIH.

En ese mismo orden desarrollaremos nuestras ideas, comenzando por un análisis de cómo los textos fundacionales de la RDP han receptado nuestro objeto de estudio y cuánto de ello permanece en el debate actual sobre el concepto en las Naciones Unidas.

\section{El derecho internacional humanitario como fundamento jurídico de la responsabilidad de proteger}

La invocación de las normas humanitarias como uno de los fundamentos jurídicos de la RDP se encuentra en su misma concepción[]]. Así, la Comisión Internacional sobre la Intervención y la Soberanía de los Estados (CIISE) sostuvo en su informe:

"Los fundamentos de la responsabilidad de proteger, como principio rector de la comunidad internacional de Estados, radican en: [...] C. las obligaciones jurídicas específicas que dimanan de las declaraciones, los pactos y los tratados relativos a los derechos humanos y la protección humana, así como del derecho internacional humanitario y el derecho interno".[4]

La CIISE amplió un poco sobre la cuestión al sostener:

"La idea de que está surgiendo un principio rector que favorece la intervención militar con fines de protección humana también encuentra respaldo en fuentes jurídicas muy diversas, incluidas las que no guardan relación con de los deberes, las responsabilidades y la autoridad que se dimanan del Capítulo VII de la Carta de las Naciones Unidas. Algunas de ellas son los principios básicos del derecho natural, las disposiciones de la Carta relativas a los derechos humanos, la Declaración Universal de Derechos Humanos, la Convención contra el Genocidio, los Convenios de Ginebra y sus Protocolos adicionales relativos al derecho internacional humanitario, el estatuto de la Corte Penal Internacional, y otros muchos acuerdos y pactos internacionales de derechos humanos y protección humana".[్]

Sin embargo, no queda claro cómo es que de las normas del DIH puede derivarse la posibilidad jurídica de una intervención militar, ni tampoco precisa cuáles serían las obligaciones de los Estados en virtud del DIH que fundarían la RDP. Se trata, entonces, de un doble juego de fundamentos jurídicos. Por un lado, los que sustentan el deber del Estado de proteger a su población de los crímenes de guerra; y, por el otro, los que sustentan la responsabilidad de la comunidad internacional de intervenir en caso de que el Estado no pueda o no quiera -en el lenguaje de la Comisiónproteger a su población. Estas dos cuestiones, insinuadas, pero no resueltas en el informe de la Comisión, coinciden con el objeto de nuestro análisis en esta sección.

La RDP ingresó en la agenda de las Naciones Unidas de la mano del Grupo de Alto Nivel para los Desafíos, las Oportunidades y el Cambio, convocado en 2003 por el entonces Secretario General Kofi Annan.[ㅌ] En su informe, el Grupo consideró que:

"El principio de la no intervención en los asuntos internos no puede utilizarse para proteger actos genocidas o atrocidades de otra índole, como infracciones en gran escala del derecho internacional humanitario o la depuración 
étnica en gran escala, que bien pueden considerarse una amenaza para la seguridad internacional y, como tal, dar lugar a que el Consejo de Seguridad tome medidas".[7] (énfasis agregado)

\section{Y luego concluye:}

"Aprobamos la norma que se está imponiendo en el sentido de que existe una responsabilidad internacional colectiva de proteger, que el Consejo de Seguridad puede ejercer autorizando la intervención militar como último recurso en caso de genocidio y otras matanzas en gran escala, de depuración étnica o de graves infracciones del derecho internacional humanitario que un gobierno soberano no haya podido o no haya querido prevenir".[] (énfasis agregado)

Pese a la contundencia de la afirmación, en el sentido de considerar que existe una "norma que se está imponiendo" respecto de la RDP, el DIH parece servir, para el Grupo de Alto Nivel, solamente como "disparador" de esta responsabilidad en caso de infracción grave de sus normas, mas no como un fundamento -al menos explícito- de la responsabilidad.

También es conocido que la RDP fue adoptada por las Naciones Unidas en los párrafos 138 y 139 del Documento Final de la Cumbre Mundial 2005, que no se refieren al DIH, pero mencionan cinco veces a los crímenes de guerra y, en su parte pertinente, disponen:

“138. Cada Estado es responsable de proteger a su población del genocidio, los crímenes de guerra, la depuración étnica y los crímenes de lesa humanidad. Esa responsabilidad conlleva la prevención de dichos crímenes, incluida la incitación a su comisión, mediante la adopción de las medidas apropiadas y necesarias. Aceptamos esa responsabilidad y convenimos en obrar en consecuencia. La comunidad internacional debe, según proceda, alentar y ayudar a los Estados a ejercer esa responsabilidad [...].

139. La comunidad internacional, por medio de las Naciones Unidas, tiene también la responsabilidad de utilizar los medios diplomáticos, humanitarios y otros medios pacíficos apropiados [...] para ayudar a proteger a las poblaciones del genocidio, los crímenes de guerra, la depuración étnica y los crímenes de lesa humanidad. En este contexto, estamos dispuestos a adoptar medidas colectivas, de manera oportuna y decisiva, por medio del Consejo de Seguridad, de conformidad con la Carta, incluido su Capítulo VII, en cada caso concreto y en colaboración con las organizaciones regionales pertinentes cuando proceda, si los medios pacíficos resultan inadecuados y es evidente que las autoridades nacionales no protegen a su población del genocidio, los crímenes de guerra, la depuración étnica y los crímenes de lesa humanidad".[]ㅡ (Énfasis agregado).

El Documento Final tampoco es explícito sobre sus fundamentos, pero hace hincapié en la prevención de los crímenes como parte de la responsabilidad del Estado de proteger a su población, y de la responsabilidad de la comunidad internacional de ayudar a los Estados a ejercerla.

A partir de 2009, el Secretario General Ban Ki-moon presentó una serie de informes anuales a la Asamblea General sobre diferentes aspectos de la RDP, una práctica que fue seguida por su sucesor, Antônio Guterres. Aunque es común hallar en estos informes menciones al DIH y sus infracciones, las referencias a las normas humanitarias como fundamento de la RDP son muy escasas.[10] En el primero de estos informes hallamos una consideración de carácter general, muy similar a la efectuada en su momento por la CIISE: 
"Hay que insistir en que las disposiciones de los párrafos 138 y 139 del Documento Final de la Cumbre están sólidamente fundadas en principios bien establecidos de derecho internacional. Tanto en el derecho internacional convencional como en el consuetudinario los Estados tienen la obligación de prevenir y sancionar el genocidio, los crímenes de guerra y los crímenes de lesa humanidad. [...] Al enunciar la responsabilidad de proteger en el Documento Final de la Cumbre no se tenía la intención de establecer excepción alguna a las obligaciones mucho más diversas vigentes en el derecho internacional humanitario, las normas internacionales de derechos humanos, el derecho de los refugiados o el derecho penal internacional".[111]

El Secretario General no profundiza sobre estos fundamentos, pero sí es claro al afirmar, por un lado, la existencia de obligaciones de los Estados de prevenir y sancionar los crímenes de guerra y, por el otro, que el Documento Final no establece ninguna excepción a las obligaciones en virtud del DIH.

Como se advierte, los textos no son claros respecto de cómo el DIH puede dar fundamento jurídico a la RDP, pero la mera invocación de sus normas es motivo suficiente para que exploremos en profundidad esta cuestión. Así, al menos tres cuestiones deben ser analizadas: en primer lugar, los crímenes de guerra como parte del contenido material de la RDP; en segundo lugar, e íntimamente relacionada con la anterior, las obligaciones generales de los Estados en virtud del DIH, tanto respecto a la responsabilidad del Estado de proteger a su propia población, como a la responsabilidad de los demás Estados de proteger otras poblaciones; y, finalmente, respecto de la relación entre el DIH y el sistema de seguridad colectiva de la Carta de las Naciones Unidas. En ese orden abordaremos tales cuestiones.

\subsection{Los crímenes de guerra como parte del contenido material de la responsabilidad de proteger}

Llamamos "contenido material" de la RDP a aquellos hechos y situaciones de los que los Estados -y, en su caso, la comunidad internacional- tienen la responsabilidad de proteger a las poblaciones, es decir, los llamados cuatro "crímenes y actos"[12]: genocidio, crímenes de guerra, crímenes de lesa humanidad y depuración étnica. Preferimos la denominación "contenido material" a la de "ámbito de aplicación", porque el uso de la palabra "aplicación" es controversial en materia de RDP. Así, sostuvo el Secretario General Ban en su tercer informe:

“... la pregunta no debe ser nunca en qué circunstancias 'se aplica' la responsabilidad de proteger. Esto da a entender equivocadamente que hay situaciones en las que los Estados no tienen una responsabilidad de proteger a sus poblaciones del genocidio, los crímenes de guerra, la depuración étnica y los crímenes de lesa humanidad. Está claro que todo Estado tiene una responsabilidad inherente de proteger".[13]

Es decir, para el Secretario General, [14] la RDP no "se aplica", dado que recae permanentemente sobre los Estados, no obstante, numerosos autores se refieran a la "aplicación" de la RDP[15]

Como dijimos, la RDP implica, entre otras cosas, la responsabilidad de todos los Estados de proteger a su población de los crímenes de guerra; por tanto, estos crímenes integran el contenido material de la RDP.

En el derecho penal internacional convencional, la definición más completa de los crímenes de guerra es la que se encuentra en el artículo 8 del Estatuto de Roma de la Corte Penal Internacional (CPI). Esta norma define a los crímenes de guerra como "infracciones graves de los Convenios de Ginebra" (art. 8.2.a), "violaciones graves de las leyes y usos aplicables en los conflictos armados internacionales" (art. 8.2.b), "violaciones graves del artículo 3 común a los Convenios de Ginebra" (art. 8.2.c) y "violaciones graves de las leyes y usos aplicables en los conflictos que no 
sean de índole internacional" (art. 8.2.e), enumerando una larga serie de conductas que constituyen tales violaciones o infracciones graves.

Lo destacable para el análisis es que, en todo caso, los crímenes de guerra constituyen violaciones del derecho aplicable a los conflictos armados[16] , es decir, del DIH, tanto codificado en los Convenios de Ginebra de 1949 y sus Protocolos adicionales de 1977, como consuetudinario[17] . Es por ello que la propia normativa humanitaria también contiene disposiciones al respecto.

Así, el artículo 85 del Protocolo adicional I[ㅌ] trata sobre las infracciones a este, y su párrafo 5 dispone: "Sin perjuicio de la aplicación de los Convenios y del presente Protocolo, las infracciones graves de dichos instrumentos se considerarán como crímenes de guerra". La disposición es relevante, en cuanto los Convenios de Ginebra no utilizan el nombre "crímenes de guerra" al referirse a las infracciones graves[19] de sus disposiciones y, como se sostuvo en la Conferencia que aprobó el Protocolo, se enfatiza la necesidad de confirmar que existe un solo concepto de crímenes de guerra, sea que el crimen específico esté definido en virtud del derecho de Ginebra, de La Haya o de Núremberg. [20] Este concepto amplio de los crímenes de guerra, que comprende las violaciones graves no solamente del derecho de Ginebra, sino de toda otra norma de DIH en la forma señalada por el artículo 8 del Estatuto de Roma, es reconocido como parte integrante del derecho consuetudinario[21] y ha tenido recepción jurisprudencial.[222]

Respecto de las obligaciones de los Estados en relación con los crímenes de guerra, el Protocolo adicional I no innova respecto de los Convenios.[23] Por su parte, estos disponen:

"Las Altas Partes Contratantes se comprometen a tomar todas las oportunas medidas legislativas para determinar las adecuadas sanciones penales que se han de aplicar a las personas que hayan cometido, o dado orden de cometer, una cualquiera de las infracciones graves contra el presente Convenio [...]. Cada una de las Partes Contratantes tendrá la obligación de buscar a las personas acusadas de haber cometido, u ordenado cometer, una cualquiera de las infracciones graves, y deberá hacerlas comparecer ante los propios tribunales, sea cual fuere su nacionalidad. Podrá también, si lo prefiere, y según las disposiciones previstas en la propia legislación, entregarlas para que sean juzgadas por otra Parte Contratante interesada, si esta ha formulado contra ellas cargos suficientes. Cada Parte Contratante tomará las oportunas medidas para que cesen, aparte de las infracciones graves [...], los actos contrarios a las disposiciones del presente Convenio".[24]

Asimismo, se sostiene la existencia de una norma similar, aplicable a todos los crímenes de guerra, en el derecho consuetudinario.[르] Existe, entonces, una obligación en cabeza de los Estados parte de los Convenios de sancionar las infracciones graves, tipificando las conductas y juzgando (o bien, extraditando) a los responsables. Lo que no encontramos en los Convenios ni en los Protocolos -y tampoco se reconoce de manera expresa como una norma consuetudinaria- es una disposición tan explícita como el artículo I de la Convención para la Prevención y Sanción del Delito de Genocidio,[26] en el sentido de que los Estados se comprometerían tanto a prevenir como a sancionar los crímenes de guerra; así, la obligación de prevención puede inferirse del deber de tomar medidas para que cesen las infracciones graves y los actos contrarios a las disposiciones de los instrumentos, así como del valor preventivo y disuasivo de las sanciones penales.[ㄹ] Por otra parte, sería absurdo sostener que existe la obligación de los Estados de reprimir los crímenes de guerra, pero no la de prevenirlos.

En definitiva, si sostenemos que los crímenes de guerra integran el contenido material de la RDP, puesto que, en virtud de esta, los Estados están obligados a proteger a su población de dichos crímenes, y estos constituyen violaciones graves del DIH, entonces, el cumplimiento de las obligaciones que emergen de las normas humanitarias implicará, para los Estados, la protección de su población de los crímenes de guerra. 


\subsection{Las obligaciones de los Estados en virtud del derecho internacional humanitario}

Habiendo aceptado que la forma de proteger a las poblaciones de los crímenes de guerra es a través del cumplimiento de las obligaciones estatales en virtud del DIH, se hace pertinente estudiar dichas obligaciones y su posible vinculación con la RDP. Con tal fin, analizaremos la obligación general de respetar y hacer respetar las disposiciones del DIH y la obligación particular de proteger a la población civil.

\subsubsection{Obligación general de respetar y hacer respetar}

En relación con las obligaciones generales, el Secretario General Ban, en uno de sus informes, trazó una posible relación con la RDP:

"La responsabilidad de proteger es compatible con las obligaciones vigentes con arreglo al derecho internacional de los derechos humanos, el derecho internacional humanitario y el derecho internacional de los refugiados, que son vinculantes para todos los Estados. [...] En el artículo 1, común a los Convenios de Ginebra, se establece la obligación de los Estados partes de velar por el respeto del derecho internacional humanitario en toda circunstancia”.[료]

Estudiaremos esta norma con detenimiento.

El artículo 1, común a los cuatro Convenios de Ginebra, dispone: "Las Altas Partes Contratantes se comprometen a respetar y a hacer respetar el presente Convenio en todas las circunstancias". De la misma manera, el artículo 1.1 del Protocolo adicional I establece: "Las Altas Partes contratantes se comprometen a respetar y hacer respetar el presente Protocolo en toda circunstancia”.

Se ha considerado que esta disposición refleja el carácter especial de los Convenios,[루 por el cual las altas partes contratantes quisieron reiterar explícitamente el principio general de que los Convenios son obligatorios y se tienen que respetar. Pero lo más complejo de interpretar es la obligación de "hacer respetar" que también está contenida en la disposición. Al respecto, se han propuesto dos enfoques.[30] De acuerdo con el primero, de concepción más restrictiva, los Estados se han comprometido a adoptar todas las medidas necesarias para asegurar el respeto de los Convenios por sus fuerzas armadas, otras entidades y grupos actuando en su nombre, y sus poblaciones en general[1] ,es decir, sus órganos y otras personas dentro de su jurisdicción. De acuerdo con el segundo enfoque, que refleja la opinión prevaleciente en la actualidad, apoyada por el Comité Internacional de la Cruz Roja (CICR), el artículo 1 requiere que los Estados aseguren el respeto de los Convenios por parte de otros Estados y grupos.[르]

Este segundo enfoque es de gran importancia para nuestro objeto de estudio, por cuanto aporta una interpretación que puede servir de fundamento, no ya para la responsabilidad del Estado de proteger, sino también de la comunidad internacional.

En este sentido, las altas partes contratantes se comprometen, sean o no partes en un conflicto armado, a asegurar el respeto de los Convenios por otras partes y Estados no partes durante un conflicto. El fundamento que se da a esta interpretación no es otro que el señalado carácter especial de los Convenios, que contienen numerosas normas que expresan "consideraciones elementales de humanidad".[33] Los intereses protegidos por los Convenios son de tan fundamental importancia para la persona humana, que cada alta parte contratante tiene un interés jurídico en su observancia y se ha sostenido que el funcionamiento adecuado del sistema de protección dispuesto en los Convenios demanda que los Estados parte, no solamente apliquen sus disposiciones, sino que también hagan todo lo que razonablemente esté a su alcance para asegurar que las disposiciones sean universalmente respetadas.[34] La Corte Internacional de Justicia $(\mathrm{CIJ})$ ha avalado esta interpretación en su opinión consultiva sobre las "Consecuencias jurídicas de la construcción de un muro en territorio palestino ocupado": 
“La Corte desea asimismo poner de relieve que el artículo 1 del Cuarto Convenio de Ginebra, disposición común a los cuatro Convenios de Ginebra, estipula que 'Las Altas Partes Contratantes se comprometen a respetar y a hacer respetar el presente Convenio en todas las circunstancias'. De esa disposición se desprende que todo Estado parte en dicho Convenio, sea o no parte en un conflicto determinado, tiene la obligación de hacer que se cumplan las exigencias impuestas por los instrumentos en cuestión".[므]

El deber de asegurar el respeto por otros comprende tanto una obligación negativa como una positiva. En virtud de la obligación negativa, las altas partes contratantes no deben alentar, ayudar ni asistir en violaciones de los Convenios cometidas por las partes en un conflicto.[ㅌ] Según la obligación positiva, deben hacer todo lo que razonablemente se encuentre a su alcance para prevenir y poner fin a tales violaciones,[37] en particular, usando su influencia en la parte infractora para hacer que vuelva a respetar los Convenios. El alcance de la obligación no se limita a detener violaciones en curso, sino que también incluye prevenir violaciones cuando existe un riesgo probable de que sean cometidas y prevenir futuras violaciones en caso de que ya hayan sido cometidas.[38] Se trata de una obligación de medios y los Estados son, en principio, libres de elegir entre diferentes posibles medidas, en cuanto se consideren adecuadas para asegurar el respeto de las disposiciones de los Convenios y, por supuesto, no sean contrarias al derecho internacional. Su contenido depende de las circunstancias específicas, incluyendo la gravedad de la violación, los medios razonablemente disponibles para el Estado, y el grado de influencia que ejerce sobre el responsable de la violación.[39] Gutiérrez Posse considera que esta obligación implica el deber de los Estados de Ilevar a cabo, en el escenario internacional, todas las acciones que estén a su alcance para intentar convencer a las partes involucradas en un conflicto armado de la necesidad de respetar las normas humanitarias, puesto que, si se cometen infracciones graves, podría activarse el deber del artículo 89 del Protocolo I.[40]En ejercicio de esta obligación, las altas partes contratantes pueden adoptar medidas individuales o colectivas, y, en ciertas situaciones, dada la especial gravedad de las violaciones, puede justificarse la adopción de medidas colectivas en el marco de la Carta de las Naciones Unidas, [41] y dar así fundamento a la actuación del Consejo de Seguridad.[42]

En este sentido, cobra especial relevancia el mencionado artículo 89 del Protocolo adicional I, que dispone: "En situaciones de violaciones graves de los Convenios o del presente Protocolo, las Altas Partes contratantes se comprometen a actuar, conjunta o separadamente, en cooperación con las Naciones Unidas y en conformidad con la Carta de las Naciones Unidas".La norma establece un deber de cooperación de las partes con las Naciones Unidas. Más allá de que se refiera a situaciones de "violaciones graves" -que no serían del todo equivalente a las "infracciones graves"-,[43] el deber deriva de la obligación general de hacer respetar, emanada del artículo 1 común y del artículo 1.1 del Protocolo, a la vez que confirma la interpretación amplia que aquí compartimos. Por otra parte, al decir, "en conformidad con la Carta de las Naciones Unidas", la norma deja en claro que no se habilita la intervención militar unilateral.

Al respecto, es muy importante señalar que esta obligación del artículo 1 no provee un argumento que justifique una desviación de las normas aplicables de derecho internacional. En particular, la existencia de la obligación de hacer respetar no justifica en sí misma que un Estado o grupo de Estados se involucren en una amenaza o uso de la fuerza contrarios al artículo 2.4 de la Carta de las Naciones Unidas[44] so pretexto de poner fin a violaciones graves de las normas humanitarias. Es decir, la obligación de hacer respetar no puede interpretarse en modo alguno que justifique la existencia de la denominada "intervención humanitaria" en el derecho internacional, ni que esta constituya una excepción a la prohibición del uso de la fuerza en el ius ad bellum. Baste para ello recordar lo que dispone sobre esta cuestión el cuarto párrafo del Preámbulo del Protocolo:

“Expresando su convicción de que ninguna disposición del presente Protocolo ni de los Convenios de Ginebra del 12 de agosto de 1949 puede interpretarse en el sentido de que legitime o autorice cualquier acto de agresión u otro uso de la fuerza incompatible con la Carta de las Naciones Unidas". 
El Comentario del CICR de 2016, al que seguimos principalmente en este análisis, afirma que las obligaciones en virtud del artículo 1 común y del artículo 89 del Protocolo adicional I existen independientemente de cualquier otro concepto, como la "responsabilidad de proteger a las poblaciones del genocidio, los crímenes de guerra, la depuración étnica y los crímenes de lesa humanidad", reconocida por la Asamblea General y el Consejo de Seguridad. [ㄴ5] El Comentario del CICR se esfuerza por diferenciar las obligaciones que surgen del artículo 1 común de la RDP. Las motivaciones detrás de este esfuerzo han de buscarse en la tradicional resistencia de las organizaciones humanitarias a que se utilice la denominación "intervención humanitaria" para las intervenciones armadas que tengan por objeto evitar o mitigar el sufrimiento humano.[46] Es cierto que existen diferencias conceptuales y de alcance entre las obligaciones del artículo 1 y la RDP: por un lado, estas obligaciones cubren muchos más supuestos que los del reducido ámbito del concepto; por el otro, el fundamento jurídico de la RDP no se agota en las normas del DIH, aplicables solamente a casos de conflicto armado, puesto que el concepto también se extiende a tiempos de paz. Pero no es menos cierto que, en cuanto ambas se superponen, las normas humanitarias permiten dar fundamento jurídico parcial- a la RDP, como surge del presente análisis.[4]]

Finalmente, caben dos consideraciones respecto del contenido de la obligación de respetar y hacer respetar, aplicables sea cual sea la interpretación que se otorgue a su alcance. Por un lado, al comprometerse a respetar y hacer respetar los Convenios, los Estados también han reconocido la importancia de adoptar todas las medidas razonables para prevenir que las violaciones ocurran en primer lugar.[48] Por el otro, el cumplimiento de las obligaciones se extiende a "toda circunstancia", es decir, no solamente a los casos de conflicto armado internacional, incluida la ocupación, según se define en el artículo 2 común, sino también a los casos de conflictos sin carácter internacional en virtud del artículo 3 común.[49] Así, las partes deben también hacer respetar las normas aplicables en conflictos armados sin carácter internacional, incluso por parte de grupos armados no estatales.[므]

De esa manera, el derecho convencional nos permite afirmar que existe una obligación general de respetar y hacer respetar las disposiciones de los Convenios y los Protocolos, y que la obligación de hacer respetar, entre otras cosas, incluye el deber de los Estados Parte, incluso si no son parte en un conflicto armado, de hacer todo lo que esté a su alcance para asegurar el cumplimiento de las mencionadas normas por las partes en el conflicto.

Podemos preguntarnos, no obstante, si este deber también existe en el derecho consuetudinario. El estudio del CICR sobre el DIH consuetudinario responde afirmativamente. Además de ratificar el carácter consuetudinario de la obligación de todo Estado de respetar y hacer respetar,[51] los dos deberes -negativo y positivo- que comprende la obligación de hacer respetar se ven reflejados en la Norma 144: "Los Estados no alentarán las violaciones del derecho internacional humanitario por las partes en un conflicto armado. En la medida de lo posible, deberán ejercer su influencia para hacer que cesen esas violaciones". [52] En fundamento de la existencia de esta norma se sostiene la aceptación casi universal de los Convenios y sus Protocolos, con el alcance asignado a la interpretación del artículo 1 común, los sucesivos llamamientos efectuados por órganos de las Naciones Unidas y conferencias internacionales, y la práctica de los Estados, en particular, respecto de Estados no partes en los Protocolos con relación a disposiciones de estos que no se encuentran en los Convenios.[్3] En particular, se hace hincapié en la naturaleza erga omnes de esta obligación,[느] en virtud de la cual, todos los Estados tienen un interés jurídico en su observancia y pueden exigir su cumplimiento. La CIJ ha sostenido:

"Es indudable que el hecho de que un gran número de normas del derecho humanitario aplicable en caso de conflicto armado sean tan fundamentales para el respeto de la persona y constituyen 'principios elementales de humanidad' [...] ha sido la causa de que los Convenios de La Haya y de Ginebra hayan sido ratificados de forma tan amplia. Además, todos los Estados han de cumplir esas normas fundamentales, hayan o no ratificado los convenios que las estatuyen, porque constituyen principios intransgredibles del derecho internacional consuetudinario".[్ㄷ] 
Por otra parte, dado que la Comisión de Derecho Internacional (CDI) ha considerado que las "normas básicas del derecho internacional humanitario" tienen carácter de ius cogens,[트] su violación grave genera las consecuencias enunciadas en el artículo 41 del Proyecto de Artículos sobre Responsabilidad del Estado por Hechos Internacionalmente llícitos, aprobado en segunda lectura en 2001 por la CDI, entre ellas, el deber de los Estados de cooperar para poner fin a la violación.[ㅍ]

Por tanto, todos los Estados están obligados a hacer respetar las normas del DIH, tanto convencional como consuetudinario. Como ha sostenido la doctrina:

“... no solo pesa la obligación de hacer por sí mismos todo lo necesario para que sus órganos y todos los que estén bajo su jurisdicción respeten las normas humanitarias (lo que entre otras cosas implica que, además de cumplir las normas en cuestión durante un conflicto armado, el Estado debe adoptar de forma preventiva medidas necesarias para asegurar el respeto del $\mathrm{DIH}$ ), sino que, sean parte o no en el conflicto, los Estados tienen que tomar todas las medidas a su alcance para garantizar que todos, y especialmente las partes en el conflicto, respeten las normas humanitarias".

[묘]

\subsubsection{Obligación de proteger a la población civil}

Además de la obligación general de respetar y hacer respetar las normas humanitarias, la obligación de proteger a la población civil también puede considerarse dentro de los fundamentos de la RDP.

EI IV Convenio de Ginebra, relativo a la protección debida a las personas civiles en tiempo de guerra, contiene numerosas normas encaminadas a ese fin, todas bajo la obligación de respetar y hacer respetar que emana del artículo 1. Al respecto, resultan de particular interés las disposiciones del Título III, "Estatuto y trato de las personas protegidas", cuyas disposiciones comunes a los territorios de las partes en conflicto y a los territorios ocupados comienzan con el artículo 27, que establece:

"Las personas protegidas tienen derecho, en todas las circunstancias, a que su persona, su honor, sus derechos familiares, sus convicciones y prácticas religiosas, sus hábitos y sus costumbres sean respetados. Siempre serán tratadas con humanidad y protegidas especialmente contra cualquier acto de violencia o de intimidación, contra los insultos y la curiosidad pública".[ㅁ9]

El Comentario del CICR de 1958 considera que esta norma ocupa una posición clave entre los artículos del Convenio: es su fundamento.[60] La norma expresa que los civiles deben ser "respetados" y "protegidos". El "deber de respetar" civiles requiere una conducta definida en términos negativos: debe evitarse todo acto que pueda causar daños injustificados a civiles. El "deber de proteger" civiles es un importante paso y exige una acción positiva. En virtud de él, debe hacerse todo lo necesario para evitar o reducir el sufrimiento; esto significa tomar todas las medidas necesarias para garantizar la seguridad de los civiles.[ㅌ1]

Este deber de protección se pone de manifiesto en ciertas normas específicas: la prohibición de usar a las personas protegidas para resguardar ciertos puntos contra las operaciones militares[르] -es decir, el uso de "escudos humanos"-; la prohibición de la coacción física y moral contra las personas protegidas;[주 la prohibición de toda medida que pueda causar sufrimientos físicos o el exterminio -que incluye el homicidio, la tortura, los castigos corporales, las mutilaciones, los experimentos médicos o científicos y cualesquiera otros malos tratos-; [64] la prohibición de los castigos colectivos, los actos de terrorismo, el pillaje y las represalias contra las personas protegidas;[65] y la prohibición de la toma de rehenes.[6] El artículo 29 es claro en establecer la responsabilidad del 
Estado -"la Parte en conflicto"- en cuyo poder se encuentren personas protegidas por el trato que les den sus agentes; allí vemos una clara conexión con la obligación general del artículo 1.[67] Por su parte, el artículo 49 aplicable a los territorios ocupados-, prohíbe los traslados forzosos en masa, así como las deportaciones de personas protegidas.[68] No deja de ser significativo que las infracciones graves, definidas en el artículo 147 del IV Convenio, [69] sean en su mayoría violaciones a estas disposiciones. Como se dijo, dado que las infracciones graves de los Convenios de Ginebra constituyen crímenes de guerra, el cumplimiento adecuado de las disposiciones protectoras del IV Convenio contribuye a la prevención de estos crímenes y, por tanto, al ejercicio de la RDP del Estado.

Podría argumentarse, no obstante, que la RDP del Estado se refiere, en los términos del Documento Final, a "su población", y las normas del IV Convenio no son directamente aplicables a los nacionales, de acuerdo con el artículo 4.[70] Sin embargo, el artículo 75 del Protocolo adicional I otorga similar protección "a las personas que estén en poder de una Parte en conflicto y que no disfruten de un trato más favorable en virtud de los Convenios o del presente Protocolo", cuando "se encuentren en una de las situaciones a que hace referencia el artículo 1 del presente Protocolo",[71] es decir, un conflicto armado internacional, lo que si bien no incluye expresamente a los propios nacionales de los Estados, tampoco los excluye.[72] Del mismo modo, el Estudio del CICR sobre el derecho consuetudinario no presenta distinción alguna respecto de los propios nacionales y considera que estas garantías fundamentales son aplicables también a casos de conflictos sin carácter internacional.[73] De otra parte, en caso de conflicto armado internacional, el Estado estaría obligado a proteger a la población de los demás Estados -bien porque pertenezca a la población del enemigo, o porque está comprendido por el deber general de "hacer respetar" del artículo 1 común-, pero no a la propia,[프] lo cual bordea el absurdo.

Además, como ha dicho la CIJ, sus disposiciones reflejan

“... la intención de los redactores del Cuarto Convenio de Ginebra de proteger a las personas civiles que se encuentren, sean cuales sean las circunstancias, en manos de la Potencia ocupante. [...] los redactores del Cuarto Convenio de Ginebra pretendían garantizar la protección de las personas civiles en tiempo de guerra, independientemente del estatuto de los territorios ocupados".[모]

Por su parte, el Protocolo adicional I sí contiene disposiciones específicas sobre un deber de protección a la población civil. Así, bajo el título "Norma fundamental", el artículo 48 dispone:

"A fin de garantizar el respeto y la protección de la población civil y de los bienes de carácter civil, las Partes en conflicto harán distinción en todo momento entre población civil y combatientes, y entre bienes de carácter civil y objetivos militares y, en consecuencia, dirigirán sus operaciones únicamente contra objetivos militares".(Énfasis agregado)

La norma, que es la consagración convencional del principio de distinción,[7]6] señala explícitamente que su finalidad no es otra que la protección de la población civil durante el conflicto armado. La CIJ ha sostenido que el principio de distinción está relacionado con la protección de la población civil y es uno de los "principios cardinales contenidos en los textos que constituyen la esencia del derecho humanitario". [77] En aplicación de este principio, el artículo 51.1 del Protocolo dispone: "1. La población civil y las personas civiles gozarán de protección general contra los peligros procedentes de operaciones militares". La norma tiene carácter consuetudinario, según se recoge en el estudio del CICR,[78] y se reitera en el artículo 57.1 del Protocolo adicional 1, que establece: "Las operaciones militares se realizarán con un cuidado constante de preservar a la población civil, a las personas y a los bienes civiles", cuyo carácter consuetudinario también se afirma.[무] 
En virtud de este principio general, tanto el IV Convenio, como el Protocolo adicional I - [무] y en algunos casos, también el Protocolo adicional II- contienen numerosas disposiciones, muchas de ellas consuetudinarias, aplicables tanto a conflicto armados internacionales como a conflictos sin carácter internacional destinadas a la protección de la población civil.

Si bien estas obligaciones recaen principalmente sobre las partes en conflicto, están comprendidas por el deber general de hacer respetar las normas del DIH y, por tanto, todos los Estados tienen interés en su observancia y pueden exigir su cumplimiento.

En virtud de lo expuesto, consideramos que surge del DIH la obligación de proteger a las poblaciones de los crímenes de guerra, la cual recae en cabeza de todos los Estados, sean o no parte en el conflicto armado de que se trate, en virtud de la obligación general de hacer respetar el DIH.

\subsection{Infracciones al derecho internacional humanitario como amenazas a la paz y la seguridad internacionales}

A partir de la década de los noventa, el DIH -y, en particular, sus infracciones- comenzó a adquirir relevancia en la práctica del Consejo de Seguridad. En ese sentido, se destacan las resoluciones que calificaron las violaciones graves del DIH como una amenaza a la paz y la seguridad internacionales, en los términos del artículo 39 de la Carta de las Naciones Unidas.[1ㅜ]

Se suele señalar que las primeras de estas resoluciones fueron la 794 (1992), sobre la situación en Somalia, y la 808 (1993), sobre la situación en la ex-Yugoslavia. En virtud de la primera, el Consejo de Seguridad expresa

“... su profunda alarma ante la constante información que recibe de violaciones generalizadas del derecho internacional humanitario en Somalia, incluidos actos y amenazas de violencia contra el personal que participa lícitamente en las actividades de socorro humanitario, ataques deliberados contra no combatientes, almacenes y vehículos de socorro, y la obstaculización de la entrega de alimentos y suministros médicos esenciales para la supervivencia de la población civil”.

Y "habiendo determinado que la magnitud de la tragedia humana causada por el conflicto en Somalia, exacerbada aún más por los obstáculos que se han venido imponiendo a la distribución de la asistencia humanitaria, constituye una amenaza a la paz y la seguridad internacionales", autorizó el uso de la fuerza "a fin de establecer cuanto antes un ambiente seguro para las operaciones de socorro humanitario en Somalia".

La segunda resolución, que creó el Tribunal Penal Internacional para la ex-Yugoslavia, el Consejo actuó "Expresando una vez más su profunda alarma ante los informes que siguen dando cuenta de violaciones generalizadas del derecho internacional humanitario en la ex-Yugoslavia, con inclusión de asesinatos en masa y la continuación de la práctica de la 'depuración étnica"” y "determinando que esta situación constituye una amenaza a la paz y la seguridad internacionales".

Esto determinó tanto la expansión del concepto de "amenaza a la paz"[르] como -lo que aquí nos interesa- un aumento de la preocupación de la comunidad internacional por las infracciones del DIH, a punto de ser susceptible de la activación del sistema de seguridad colectiva previsto en el Capítulo VII de la Carta.[으]

Desde entonces, el Consejo de Seguridad ha prestado especial atención a la cuestión de las violaciones del DIH no solamente en casos particulares, sino también de manera general bajo el tema "Protección de civiles en conflictos", que resulta de particular interés para nuestro análisis. Así, en la Resolución 1296 (2000), observó 
“... que los ataques dirigidos deliberadamente contra las poblaciones civiles $u$ otras personas protegidas y las violaciones sistemáticas, manifiestas y generalizadas del derecho internacional humanitario y del derecho internacional relativo a los derechos humanos en situaciones de conflicto armado pueden constituir una amenaza para la paz y la seguridad internacionales y, a este respecto, reafirma que está dispuesto a examinar esas situaciones y, cuando sea necesario, imponer medidas adecuadas".[누]

Así, el Consejo de Seguridad reconoce que las violaciones "sistemáticas, manifiestas y generalizadas" [모] del DIH pueden[ㅌ] constituir en sí mismas una amenaza a la paz y la seguridad internacionales, lo que le permite, de ser necesario, "imponer medidas adecuadas", que no son otras que las previstas en el Capítulo VII de la Carta.

Además, fue en las resoluciones sobre esta cuestión que el Consejo de Seguridad hizo suya la RDP. En la Resolución 1674 (2006), el Consejo reafirmó "las disposiciones de los párrafos 138 y 139 del Documento Final de la Cumbre Mundial 2005 respecto de la responsabilidad de proteger a las poblaciones del genocidio, los crímenes de guerra, la depuración étnica y los crímenes de lesa humanidad”. [87] Esto requiere unas precisiones. El Consejo de Seguridad ha debatido la RDP principalmente en el contexto del tratamiento de este tema,[88] y no son, sin embargo, sinónimos [무] . Por un lado, la protección de civiles en conflictos cubre un espectro mucho más amplio que la RDP, tanto por su contenido material como por el alcance de las medidas que pueden tomarse. Por otra parte, las situaciones que abarca el contenido material de la RDP no se dan necesariamente dentro de un conflicto armado, por lo que podría tratarse de una situación que no se incluya en el tema de protección de civiles en conflictos.

Sin embargo, no puede negarse que existe una íntima relación entre el cumplimiento de las normas del DIH, la protección de civiles en conflictos y la RDP, como lo advertimos en el más sonado caso de ejercicio de la RDP por parte del Consejo de Seguridad: la situación en Libia en 2011.[ㅁ] Así, en la Resolución 1973 (2011), el Consejo actuó "Reiterando que las autoridades libias tienen la responsabilidad de proteger a la población libia y reafirmando que las partes en los conflictos armados tienen la responsabilidad primordial de adoptar todas las medidas posibles para asegurar la protección de los civiles"[91] y, "habiendo determinado que la situación imperante en la Jamahiriya Árabe Libia sigue representando una amenaza para la paz y la seguridad internacionales”,[으] exigió.

“... que las autoridades libias cumplan las obligaciones que les impone el derecho internacional, incluido el derecho internacional humanitario, las normas de derechos humanos y el derecho de los refugiados, y adopten todas las medidas necesarias para proteger a los civiles, satisfacer sus necesidades básicas y asegurar el tránsito rápido y sin trabas de la asistencia humanitaria".[으]

Aunque esta relación, como hemos visto, no sea directa -por cuanto la posibilidad de decidir medidas colectivas en virtud del Capítulo VII de la Carta no se deriva necesariamente de las obligaciones de los Estados según el DIH,[94] sino de la propia práctica del Consejo de Seguridad y su ampliación del concepto de "amenaza a la paz"-, ha sido reconocida, tal vez tímidamente, en los desarrollos sobre la RDP en las Naciones Unidas, a través de una nota del Secretario General Guterres, en la que expresó:

"El Consejo de Seguridad ha reconocido que los ataques dirigidos deliberadamente contra civiles y otras violaciones flagrantes y sistemáticas del derecho internacional humanitario y de los derechos humanos pueden constituir una amenaza para la paz y la seguridad internacionales (véase el párrafo 26 de la Resolución 1674 (2006))"[모

\section{El tercer pilar de la responsabilidad de proteger y el cumplimiento del derecho internacional humanitario}


La vinculación del DIH con la RDP no se agota en los fundamentos de esta última, sino que también incluye la aplicación de las normas humanitarias a las intervenciones armadas ejecutadas en ejercicio de la RDP de la comunidad internacional, en virtud de su denominado "tercer pilar".

La cuestión se inserta en la vieja discusión de si el DIH se aplica a intervenciones armadas decididas en el marco del sistema de seguridad colectiva,[96] discusión que surge a partir de dos argumentos que niegan la aplicación de las normas humanitarias en la especie: el primero, relacionado con la diferencia moral entre las partes en un conflicto según la cual el o los Estados que intervienen para mantener o restablecer la paz y la seguridad internacionales no pueden estar sujetos a las mismas obligaciones que el agresor -o, en nuestro caso, el Estado que no protege a su población-;[97] y el segundo, fundado en que una intervención de tal naturaleza implicará la decisión de una autoridad competente como el Consejo de Seguridad (la que conservará cierto grado de dirección o control sobre la operación), que sostiene que al no ser la organización internacional quien decide la intervención parte en los Convenios de Ginebra -que solamente están abiertos a los Estados-,[98] las operaciones decididas por aquella no estarían alcanzadas por las disposiciones de los Convenios.

Ambos argumentos deben ser descartados. El primero, por cuanto se enfrenta con el obstáculo insalvable de la obligación de respetar y hacer respetar las normas humanitarias "en toda circunstancia", según surge expresamente del artículo 1 común a los Convenios de Ginebra y del artículo 1.1 del Protocolo adicional I.

El segundo argumento choca con la realidad de que las fuerzas que aportan los Estados para una operación multinacional -como sería el caso de una intervención armada en ejercicio de la RDP- permanecen siempre bajo cierto grado de control de sus respectivos Estados, y en la medida en que estos conservan su autoridad, continúan obligados a respetar y hacer respetar las normas convencionales en virtud del artículo 1 común a los Convenios de Ginebra..[99] Por otra parte, aunque es verdad que las organizaciones internacionales no son ni pueden ser parte de los tratados de DIH, sí pueden estar vinculadas por el derecho consuetudinario.[100] Las propias Naciones Unidas reconocieron esta circunstancia y el Secretario General Annan, a través de un Boletín, dispuso la observancia de las normas de DIH por parte de las fuerzas de las Naciones Unidas.[101]

Por otra parte, resultaría un sinsentido que las fuerzas que intervienen en un Estado en ejercicio de la RDP no estuvieran obligadas a respetar las normas del $\mathrm{DIH}$, cuando fue el incumplimiento manifiesto de estas normas lo que motivó en primer lugar la intervención. Pese a ello, la cuestión no ha tenido una amplia recepción en la discusión en torno a dicha responsabilidad.

La CIISE sí lo tuvo presente al momento de su concepción, al sostener, en línea con lo que planteamos:

"Es obvio que en estas situaciones han de respetarse plenamente las normas del derecho internacional humanitario. De hecho puede argumentarse que en casos así deberían aplicarse normas aún más estrictas, puesto que la intervención conlleva un tipo de acción militar que tiene un objetivo mucho más preciso y específico que la guerra total".[102]

También expresó en su informe:

"En el contexto de las intervenciones emprendidas con fines de protección humana, las reglas de combate de una intervención militar han de respetar estrictamente las disposiciones del derecho internacional y en particular del 
derecho internacional humanitario. Además debe reconocerse explícitamente que no pueden emplearse ciertos tipos de armas, en concreto las prohibidas por ciertos acuerdos internacionales".[103]

Ya en el marco de la discusión en las Naciones Unidas, la cuestión vino de la mano de la propuesta brasileña de la "Responsabilidad al Proteger", una iniciativa surgida luego de la intervención en Libia y que tenía por objeto pronunciarse sobre las cuestiones más polémicas de la intervención armada en virtud del tercer pilar de la RDP. Expresaba la propuesta:

"En el ejercicio de su responsabilidad de proteger, la comunidad internacional debe dar muestras de una gran responsabilidad al facilitar la protección. Ambos conceptos deben evolucionar juntos, sobre la base de un conjunto acordado de principios fundamentales, parámetros y procedimientos, como los siguientes: [...] d) La autorización del uso de la fuerza debe limitarse a sus elementos jurídicos, operacionales y temporales, y el alcance de la acción militar debe atenerse a la letra y el espíritu del mandato dado por el Consejo de Seguridad o la Asamblea General, y debe llevarse a cabo en estrictocumplimiento del derecho internacional, en particular el derecho internacional humanitario y el derecho internacional de los conflictos armados".[104](Énfasis agregado).

Es notable que, pese a que la CIISE se refirió a la cuestión, y Brasil insistió al respecto en su propuesta, en ninguno de los informes del Secretario General sobre la RDP se abordó en profundidad la temática,[105] ni siquiera en el relativo al tercer pilar, en el que la cuestión de la intervención armada fue tratada de manera casi incidental, pese a que el Secretario comentó la iniciativa brasileña. En ese sentido, la única referencia significativa que podemos destacar es la siguiente:

"La experiencia de Libia sirve para recordarnos la importancia de que los actores militares tomen todas las precauciones posibles para evitar situaciones que pongan en peligro a civiles, de acuerdo con el derecho internacional que regula las hostilidades armadas, e investiguen las posibles violaciones del derecho internacional cometidas en esos contextos".[106]

Es decir, el Secretario General reconoce la aplicación de las normas del DIH a las intervenciones de RDP, pero no profundiza sobre la cuestión ni la trata en términos generales.

Esto no es más que la consecuencia de la estrategia adoptada por los secretarios generales en torno al tratamiento que la RDP tiene en las Naciones Unidas: construir el consenso en torno a los aspectos menos discutidos del concepto evitando los más controversiales. Es evidente que el tercer pilar, y en particular, la intervención armada, está en el punto álgido de la discusión, y es prácticamente ignorado por los informes. De allí que la aplicación del DIH a las situaciones de intervención no reciba más que una mención incidental.

Esto no implica que se rechace la aplicación del DIH a las intervenciones armadas en virtud del tercer pilar de la RDP. Como aquí se demuestra, los fundamentos que lo justifican son sólidos, basados en normas fundamentales del DIH y ello resulta, como se dijo, de toda lógica, teniendo en cuenta las motivaciones de la propia intervención.

\section{Consideraciones finales}

Creemos que el análisis que antecede ha permitido demostrar la relación dual que planteamos inicialmente entre el DIH y la RDP, en la que las normas humanitarias actúan como fundamento y límite de este nuevo concepto. En primer lugar, todos los Estados están obligados a proteger a las poblaciones de los crímenes de guerra, es decir, de las 
violaciones graves del $\mathrm{DIH}$; esto es aplicable tanto en caso de conflicto armado internacional como no internacional. Este deber se desprende no solamente de las normas específicas en materia de crímenes de guerra, sino, y principalmente, de la obligación general de respetar y hacer respetar las normas del $\mathrm{DIH}$, tanto convencional como consuetudinario. En particular, la obligación de "hacer respetar" constituye un importante fundamento para sostener la responsabilidad de la comunidad internacional de "ayudar a proteger" a las poblaciones, por cuanto implica el deber de los Estados de hacer todo lo que esté a su alcance por que las partes en conflicto respeten las normas humanitarias, dentro del marco del derecho internacional.

Pero el análisis también demostró que esta afirmación admite algunas precisiones. Dado el limitado ámbito de aplicación del DIH, solamente sirve de fundamento a la RDP en caso de conflicto armado.[108] Es decir que, si bien aceptamos que las normas humanitarias incluyen numerosas disposiciones que generan la obligación de los Estados de proteger, tanto a su población como a la población de otros Estados, con base en consideraciones generales de humanidad, no podemos negar que esta protección solamente regirá en caso de conflicto armado, tanto internacional como interno, pero no se aplica a tiempos de paz. El fundamento que otorga el DIH es, entonces, insuficiente. De allí que la RDP requiera, entre otras cosas, también del DIDH para completarlo.

Por otra parte, y como señalara el Comentario del CICR al I Convenio de Ginebra, la obligación de hacer respetar, y los deberes a ella asociados, no se identifica con la RDP, pero pensamos que eso no implica negar que esta obligación pueda servirle de fundamento. Tampoco se advierte que de esta sola obligación derive necesariamente el deber de la comunidad internacional de adoptar medidas colectivas cuando un Estado no proteja a su población de los crímenes de guerra, pero para ello es fundamental entender la evolución del concepto de "amenaza a la paz" en la práctica del Consejo de Seguridad, y el lugar que ocupan las violaciones del DIH. En ese sentido, la Carta de las Naciones Unidas otorga suficiente fundamento a la acción colectiva en caso de estas violaciones.

También creemos haber demostrado que la RDP no otorga carta blanca para la intervención armada. Si esta se decide por el Consejo de Seguridad, debe cumplir con las disposiciones del DIH, tanto en virtud de las normas aplicables que así lo establecen como del imperativo moral que motiva una intervención de estas características.

El análisis también arrojó un dato que no es menor: la virtual ausencia de la discusión en torno a los fundamentos jurídicos $-\mathrm{y}$, en lo que nos interesa, los referidos al DIH- en el debate sobre la RDP en las Naciones Unidas. Ello puede deberse, o bien a considerar como una obviedad estos fundamentos, por tratarse de normas muy aceptadas por la comunidad internacional -a pesar de sus continuas violaciones-, o, lo que nos parece más grave, una reticencia a avanzar en la consolidación de los aspectos normativos de la RDP. Esperamos, en estas líneas, haber realizado un aporte para incentivar y profundizar esta discusión.

\section{Referencias}

[1] Helen Durham y Phoebe Wynn-Pope, "The relationship between international humanitarian law and responsibility to protect: From Solferino to Srebrenica”, en Angus Francis, Vesselin Popovski y Charles Sampford (eds.), Norms of protection: Responsibility to protect, protection of civilians and their interaction, Tokio, United Nations University Press, 2013, pp. 175-196.

[2] Aunque los autores reconocen, al igual que varios de los textos fundamentales en materia de RDP, que el DIH puede dar fundamento a la RDP (Hugh Breakey, "The responsibility to protect: Game change and regime 
change", en Francis, Popovski y Sampford, Norms of protection, op. cit., pp. 11-39; Siobhán Wills, Protecting Civilians, Oxford, Oxford University Press, 2009, p. 108), no hay en la literatura especializada un estudio detenido sobre esta cuestión.

[3] El concepto de RDP fue acuñado en 2001 por la Comisión Internacional sobre Intervención y Soberanía de los Estados, creada en 2000 por el Gobierno de Canadá como respuesta al denominado "dilema de la intervención", con el que el por entonces Secretario General de las Naciones Unidas, Kofi Annan, interpeló a los Estados luego de la intervención de la otan en Kosovo (ver Luciano Pezzano, La responsabilidad de proteger en las Naciones Unidas, Córdoba, Centro de Estudios Avanzados-Advocatus, 2016, pp. 44-53).

[4] Comisión Internacional sobre Intervención y Soberanía de los Estados, La responsabilidad de proteger, Ottawa, Informe de la Comisión Internacional sobre Intervención y Soberanía de los Estados, 2001, p. xi.

[]ㅣ/bid., p. 17.

[6] Luciano Pezzano, La responsabilidad de proteger en las Naciones Unidas, op. cit., pp. 53-56.

[7] Grupo de Alto Nivel, "Un mundo más seguro: la responsabilidad que compartimos. Informe del Grupo de Alto Nivel sobre las amenazas, los desafíos y el cambio", nota del Secretario General, UN.Doc.A/59/565, Nueva York, Naciones Unidas, 2004, párr. 200.

[]]/bid., párr. 203.

[9] Asamblea General de las Naciones Unidas, Documento Final de la Cumbre Mundial 2005, Resolución 60/1, Nueva York, Naciones Unidas, 2005.

[10] También son escasas las referencias a los fundamentos en los debates de la Asamblea General. Al respecto, cabe mencionar lo que sostuvo el representante de Costa Rica en el debate de 2019: "El principio de la responsabilidad de proteger se conceptualizó en consonancia con las obligaciones de los Estados -en virtud del derecho internacional, el derecho internacional humanitario y el derecho de los derechos humanos- de no cometer violaciones sistemáticas de los derechos humanos de la población civil", Asamblea General de las Naciones Unidas, "Acta literal de la 93a sesión plenaria", UN.Doc.A/73/PV.93, Nueva York, Naciones Unidas, 2019, p. 13.

[11] Ban Ki-moon, "Hacer efectiva la responsabilidad de proteger. Informe del Secretario General", UN.Doc.A/63/677, Nueva York, Naciones Unidas, 2009, párr. 2.

[12] La expresión "crímenes y actos" es utilizada para comprender, no solamente los tres crímenes de derecho internacional (genocidio, crímenes de guerra y crímenes de lesa humanidad), sino también la depuración étnica, que no es en sí misma un crimen, aunque puede implicar una combinación de ellos: Ban Ki-moon, "La responsabilidad de proteger: responsabilidad del Estado y prevención. Informe del Secretario General", UN.Doc.A/67/929-S/2013/399, Nueva York, Naciones Unidas, 2013, p. 4, nota 2. Sobre ciertas polémicas en torno a esta denominación, ver Alex J. Bellamy, "Making RtoP a living reality: Reflections on the 2012 General Assembly Dialogue on Timely and Decisive Response", Global Responsibility to Protect 1 (2013), pp. 109-125.

[13] Ban Ki-moon, "La responsabilidad de proteger: respuesta oportuna y decisiva. Informe del Secretario General”, UN.Doc.A/66/874-S/2012/578, Nueva York, Naciones Unidas, 2012, párr. 13.

[14] Aunque, en un informe posterior, el Secretario General parece contradecirse, al referirse explícitamente al "ámbito de aplicación" de la RDP: Ban Ki-moon, "Cumplimiento de nuestra responsabilidad colectiva: asistencia 
internacional y la responsabilidad de proteger. Informe del Secretario General", UN.Doc.A/68/947-S/2014/449, Nueva York, Naciones Unidas, 2014, párr. 79.

[15] La lista es amplia; solo a título de ejemplo podemos señalar: Ricardo Arredondo, Intervención humanitaria y responsabilidad de proteger. ¿Hacia un nuevo paradigma de protección de los derechos humanos?, Buenos Aires, Catálogos, 2012 passim; Isabel García Martin, "El principio de la responsabilidad de proteger: ¿supone una nueva excepción al uso de la fuerza?", Revista Enfoques: Ciencia Política y Administración Pública, 27 (2017), pp. 173-193; Sheri P. Rosenberg y Ekkehard Strauss, "A common standard for applying R2P”, Cardozo Law, 2013, en www.globalr2p.org/media/files/r2p_standards_policy_letter-1.pdf, fecha de consulta: 14 de junio de 2019; Jennifer Welsh, "Implementing the 'responsibility to protect"', Policy Brief 1 (2009), p. 4.

[16] Kai Ambos, Nociones básicas del derecho internacional humanitario, Valencia, Tirant lo Blanch, 2011, p. 20.

[17] Helen Durham y Phoebe Wynn-Pope, "The relationship between international humanitarian law and responsibility to protect, op. cit., p. 187.

[18] Protocolo I adicional a los Convenios de Ginebra de 1949 relativo a la protección de las víctimas de los conflictos armados internacionales, 1977.

[19] Esto se explica por cuanto, según el artículo 8 del Estatuto de Roma, el concepto de "crímenes de guerra" es más amplio que las infracciones graves de los Convenios de Ginebra, por cuanto comprende a estas y otro tipo de violaciones (CICR, Commentary on the First Geneva Convention: Convention (I) for the Amelioration of the Condition of the Wounded and Sick in Armed Forces in the Field), 2 ed.,2016, párr. 2821, en ihldatabases.icrc.org/ihl/full/GCl-commentary., fecha de consulta: 14 de junio de 2019.

[20] Yves Sandoz, Christophe Swinarski y Bruno Zimmermann, Commentary on the Additional Protocols of 8 June 1977 to the Geneva Conventions of 12 August 1949, Ginebra, Comité Internacional de la Cruz Roja, 1987, p. 1003.

[21] Jean-Marie Henckaerts y Louise Doswald-Beck, El derecho internacional humanitario consuetudinario, Ginebra, Comité Internacional de la Cruz Roja, 2007.

[22] TPIY, Prosecutor v. Duško Tadić a.k.a. "Dule", Decision on the Defence Motion for Interlocutory Appeal on Jurisdiction, 2 de octubre de 1995, párr. 87.

[23] Protocolo I adicional a los Convenios de Ginebra de 1949 relativo a la protección de las víctimas de los conflictos armados internacionales, 1977, artículo 85.1.

[24] Convenio de Ginebra para aliviar la suerte que corren los heridos y los enfermos de las fuerzas armadas en campaña, 1949, Convenio I, artículo 49; Convenio de Ginebra para aliviar la suerte que corren los heridos, los enfermos y los náufragos de las fuerzas armadas en el mar, 1949, Convenio II, artículo 50; Convenio de Ginebra relativo al trato debido a los prisioneros de guerra, 1949, Convenio III, artículo 129; Convenio de Ginebra relativo a la protección debida a las personas civiles en tiempo de guerra, 1949, Convenio IV, artículo 146.

[25] Henckaerts y Doswald-Beck, El derecho internacional humanitario consuetudinario, op. cit., pp. 643 y ss.

[26] Que dispone: "Las Partes contratantes confirman que el genocidio, ya sea cometido en tiempo de paz o en tiempo de guerra, es un delito de derecho internacional que ellas se comprometen a prevenir y a sancionar".

[27] CICR, Commentary on the First Geneva Convention,op. cit., párr. 2842. 
[28] Ban Ki-moon, "La responsabilidad de proteger: responsabilidad del Estado y prevención. Informe del Secretario General”, UN.Doc.A/67/929-S/2013/399, Nueva York, Naciones Unidas, 2013, párr. 6.

[29] CICR, Commentary on the First Geneva Convention,op. cit., párr. 118.

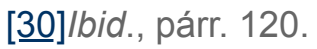

[31]/bid., párr. 118.

[르]/bid., párr. 120.

[33] International Court of Justice, "Legality of the threat or use of nuclear weapons", Advisory Opinion, 1996, p. 226, párr. 79.

[34] CICR, Commentary on the First Geneva Convention,op. cit., párr. 119.

[35] International Court of Justice, "Legal consequences of the construction of a wall in the occupied Palestinian Territory", Advisory Opinion, 2004,p. 136, párr. 158.

[36] La existencia de esta obligación negativa fue reconocida por la Corte Internacional de Justicia (CIJ): "The Court considers that there is an obligation on the United States Government, in the terms of Article 1 of the Geneva Conventions, to "respect" the Conventions and even "to ensure respect" for them "in all circumstances", since such an obligation does not derive only from the Conventions themselves, but from the general principles of humanitarian law to which the Conventions merely give specific expression. The United States is thus under an obligation not to encourage persons or groups engaged in the conflict in Nicaragua to act in violation of the provisions of Article 3 common to the four 1949 Geneva Conventions"(ICJ, "Military and paramilitary activities in and against Nicaragua [Nicaragua v. United States of America], Merits, Judgment”, 1986, p. 14, párr. 220).

[37] CICR, Commentary on the First Geneva Convention,op. cit., párr. 154.

[료]/bid., 164.

[39]]/bid., párr. 165.

[40] Hortensia Gutiérrez Posse, Elementos de derecho internacional humanitario, Buenos Aires, Eudeba, 2014, p. 227.

[41] CICR, Commentary on the First Geneva Convention,op. cit., párr. 178.

[42] Marco Roscini, "The United Nations Security Council and the enforcement of international humanitarian law", Israel Law Review 43, 2 (2010), pp. 330-359.

[43] Sandoz, Swinarski y Zimmermann, Commentary on the Additional Protocols, op. cit., párr. 3589-3593.

[44] CICR, Commentary on the First Geneva Convention,op. cit., párr. 174.

[45] Ibid., párr. 179.

[46] Que oportunamente advirtiera la CIISE y que, incluso, motivó el abandono de la noción -errónea e ilegal a nuestro entender- de "intervención humanitaria" y la misma acuñación del concepto de RDP. 
[47] En el mismo sentido, ver Durham y Wynn-Pope, "The relationship between international humanitarian law and responsibility to protect", op. cit., pp. 190 y ss.

[48] CICR, Commentary on the First Geneva Convention,op. cit., párr. 121.

[49]/lbid., párr. 125.

[미] Esto fue confirmado por la ClJ, ver nota 36.

[51] Norma 139: "Las partes en conflicto deberán respetar y hacer respetar el derecho internacional humanitario por sus fuerzas armadas, así como por otras personas y agrupaciones que actúen de hecho siguiendo sus instrucciones o bajo su dirección o control"(Henckaerts y Doswald-Beck, El derecho internacional humanitario consuetudinario, op. cit., p. 559).

[르]/bid., p. 575.

[53] $]$ /bid., pp. 576-579.

[54] Que fue reconocida por el TPIY (TPIY, Prosecutor v. Kupreskic et al. Decision on evidence of the good character of the accused and the defence of tu quoque, 17 de febrero de 1999).

[도] CIJ, Legality of the threat or use of nuclear weapons, cit.,p. 226, párr. 79.

[드] Proyecto de conclusión 23, del Proyecto de conclusiones sobre normas imperativas del derecho internacional general (ius cogens), aprobado por el Comité de Redacción CDI, "Normas imperativas de derecho internacional general (ius cogens). Texto del proyecto de conclusiones y del proyecto de anexo aprobados provisionalmente por el Comité de Redacción en primera lectura”, UN.Doc.A/CN.4/L.936, Ginebra, Naciones Unidas, 2019.

[57] Andreas S. Kolb, The UN Security Council Members' Responsibility to Protect. A Legal Analysis, Berlin, Springer, 2018, p. 285.

[됴] María Teresa Comellas Aguirrezábal, La incidencia de la práctica del Consejo de Seguridad en el Derecho Internacional Humanitario, Pamplona, Thomson-Aranzadi, 2007, pp. 220-221.

[두] Convenio de Ginebra relativo a la protección debida a las personas civiles en tiempo de guerra, 1949, Convenio IV, artículo 27.1.

[60] Jean Pictet (dir.), Commentary on the Geneva Convention relative to the protection of civilian persons in time of war, Ginebra, CICR, 1958, p. 200.

[61] Hans-Peter Gasser y Knut Dörmann, "Protection of the Civilian Population", en Dieter Fleck (ed.), The Handbook of International Humanitarian Law, Oxford, Oxford University Press, 2013, pp. 231-320.

[62] Convenio de Ginebra relativo a la protección debida a las personas civiles en tiempo de guerra, cit., artículo 28. Ver también Protocolo adicional I, artículo 51.7 y Norma 97 del Estudio del CICR (Henckaerts y DoswaldBeck, El derecho internacional humanitario consuetudinario,op. cit., pp. 384-387).

[63] Convenio de Ginebra relativo a la protección debida a las personas civiles en tiempo de guerra, cit., artículo 31. 
[64] Convenio de Ginebra relativo a la protección debida a las personas civiles en tiempo de guerra, 1949, Convenio IV, artículo 32. Ver también Protocolo adicional I, artículo 75.2.a) y Normas 89, 90, 91 y 92 del Estudio del CICR (Henckaerts y Doswald-Beck, El derecho internacional humanitario consuetudinario, op. cit., pp. 359368).

[65] Convenio de Ginebra relativo a la protección debida a las personas civiles en tiempo de guerra, cit., artículo 33. El comentario del CICR señala que la prohibición de las represalias está íntimamente vinculada con las disposiciones que, al garantizar que los convenios se apliquen en todas las circunstancias, le dan el carácter de un deber primario basado esencialmente en la protección de la persona humana (Pictet, Commentary on the Geneva Convention,op. cit., p. 228). Ver también Protocolo adicional I, cit., artículo 75.2.d, y Normas 103 y 146 del Estudio del CICR (Henckaerts y Doswald-Beck, El derecho internacional humanitario consuetudinario, op. cit., pp. 426-427.

[66] Convenio de Ginebra relativo a la protección debida a las personas civiles en tiempo de guerra, cit., artículo 34. Ver también Protocolo adicional I, cit., artículo 75.2.c); Norma 96 del Estudio del CICR (Henckaerts y DoswaldBeck, El derecho internacional humanitario consuetudinario, op. cit., pp. 381-383.

[67] Pictet, Commentary on the Geneva Convention, op. cit., p. 210.

[요] Ver también Norma 129 del Estudio del CICR (Henckaerts y Doswald-Beck, El derecho internacional humanitario consuetudinario, op. cit., pp. 517-521).

[69]“Las infracciones graves a las que se refiere el artículo anterior son las que implican uno cualquiera de los actos siguientes, si se cometen contra personas o bienes protegidos por el Convenio: el homicidio intencional, la tortura o los tratos inhumanos, incluidos los experimentos biológicos, el hecho de causar deliberadamente grandes sufrimientos o de atentar gravemente contra la integridad física o la salud, la deportación o el traslado ilegal, la detención ilegal, el hecho de forzar a una persona protegida a servir en las fuerzas armadas de la Potencia enemiga, o el hecho de privarla de su derecho a ser juzgada legítima e imparcialmente según las prescripciones del presente Convenio, la toma de rehenes, la destrucción y la apropiación de bienes no justificadas por necesidades militares y realizadas a gran escala de modo ilícito y arbitrario".

[70] Ver Pictet, Commentary on the Geneva Convention, op. cit., p. 46.

[71] Protocolo I adicional a los Convenios de Ginebra, cit., artículo 75.1.

[72] Ver Sandoz, Swinarski y Zimmermann, Commentary on the Additional Protocols, op. cit., párr. 3017 y ss.

[73] Henckaerts y Doswald-Beck, El derecho internacional humanitario consuetudinario, op. cit., cap. 32.

[74] Podría sostenerse que las obligaciones del Estado de proteger a su propia población derivan no del DIH, sino de sus obligaciones en materia de derechos humanos, las que, como ha sostenido la CIJ, no cesan en caso de conflicto armado (ICJ, "Legality of the threat or use of nuclear weapons", cit.,p. 226, párr. 25; "Legal Consequences of the construction of a wall in the occupied palestinian territory", cit., p. 136, párr. 106). Sin embargo, por las razones expuestas en el texto, la interpretación evolutiva de las normas humanitarias permite ampliar la protección de estas a los propios nacionales.

[도] ICJ, "Legal consequences of the construction of a wall in the occupied palestinian territory", cit., p. 136, párr. 95.

[76] Gutiérrez Posse, Elementos de Derecho Internacional Humanitario, op. cit., pp. 71 y ss. 
[77] ICJ, "Legality of the threat or use of nuclear weapons", cit., p. 226, párr. 78.

[묘] Ver Norma 6 (Henckaerts y Doswald-Beck, El derecho internacional humanitario consuetudinario, op. cit., p. 22 y ss.).

[79] Ver Norma 15 (ibid., pp. 59 y ss.).

[ㅇ] Protocolo II adicional a los Convenios de Ginebra de 1949, relativo a la protección de las víctimas de los conflictos armados sin carácter internacional, 1977, artículo 13.

[81] Kolb, The un Security Council Members' Responsibility to Protect,op. cit., pp. 422-424.

[82] Ver Nico Krisch, "Article 39", en Bruno Simma et al. (eds.), The Charter of the United Nations: A Commentary, Oxford, Oxford University Press, 2012, pp. 1278-1293.

[83] Roscini, "The United Nations Security Council and the enforcement of international humanitarian law", op. cit., pp. 332-337.

[84] Consejo de Seguridad de las Naciones Unidas, Resolución 1296 (2000), párr. 5. El Consejo reiteró esta observación en sus resoluciones 1674 (2006), párr. 26; 1738 (2006), párr. 9; y 1894 (2009), párr. 3.

[85] Curiosamente, no se refiere a las "violaciones graves", como sí lo hacen las normas humanitarias, como el citado artículo 89 del Protocolo adicional I, relativo a la cooperación con las Naciones Unidas.

[드] Sobre el significado de "puede", ver Erika de Wet, The Chapter VII Powers of the United Nations Security Council, Oxford, Hart Publishing, 2004, p. 175.

[87] Consejo de Seguridad de las Naciones Unidas, Resolución 1674 (2006), párr. 4. Reiterado en Resolución 1894 (2009), preámbulo, séptimo párrafo.

[88] Pezzano, La Responsabilidad de Proteger en las Naciones Unidas, op. cit., p. 84.

[우 Sobre la relación, ver Hugh Breakey, "Protection norms and human rights: A rights-based analysis of the responsibility to protect and the protection of civilians in armed conflict", Global Responsibility to Protect 3 (2012), pp. 309-333.

[ㅁ] Al respecto, ver Pezzano, La Responsabilidad de Proteger en las Naciones Unidas, op. cit., pp. 135 y ss., y los autores allí citados.

[91] Consejo de Seguridad de las Naciones Unidas, Resolución 1973 (2011), preámbulo, párr. 4.

[92]/bid., párr. 21.

[93] /bid., párr. 3.

[94] Comellas Aguirrezábal, La incidencia de la práctica del Consejo de Seguridad, op. cit., pp. 228-230.

[95] Antônio Guterres, La aplicación de la responsabilidad de proteger: la rendición de cuentas en materia de prevención. Informe del Secretario General, Nueva York, Naciones Unidas, 2017, p. 16, nota 11. 
[96] Ver de Wet, The Chapter VII Powers of the United Nations Security Council, op. cit., pp. 204 y ss.

[97] Ver el tratamiento de los argumentos y su refutación en François Bugnion, “Just wars, wars of aggression and international humanitarian law”, International Review of the Red Cross 849 (2003), pp. 3-26.

[요 Y a los pueblos, a través de los movimientos de liberación nacional (art. 96.3 del Protocolo adicional I). Ver Luciano Pezzano, "Los Movimientos de Liberación Nacional en el pensamiento de Julio A. Barberis", Cuadernos de Derecho Internacional IX (2015), pp. 211-242.

[99] CICR, Commentary on the First Geneva Convention,op. cit., párr. 133-137.

[100] Christopher Greenwood, "International Humanitarian Law and United Nations Military Operations", Yearbook of International Humanitarian Law 1 (1998), pp. 3-34.

[101] Secretario General de las Naciones Unidas, Observance by United Nations forces of international humanitarian law, UN.Doc.ST/SGB/1999/13, Nueva York, Naciones Unidas, 1999. Para un análisis, ver Keiichiro Okimoto, "Violations of international humanitarian law by United Nations forces and their legal consequences", Yearbook of International Humanitarian Law 6 (2003), pp. 199-236.

[102] CIISE, La responsabilidad de proteger, op. cit., p. 41.

[103]/bid., p. 67.

[104] Naciones Unidas, "Carta de fecha 9 de noviembre de 2011, dirigida al Secretario General por la Representante Permanente de Brasil ante las Naciones Unidas", UN.Doc.A/66/551-S/2011/701, Nueva York, Naciones Unidas, 2011, Anexo, párr. 11.

[105] Entre 2009 y 2019, los Secretarios Generales, Ban y Guterres presentaron once informes sobre la RDP.

[106] Ban Ki-moon, La responsabilidad de proteger: respuesta oportuna y decisiva, cit., párr. 55.

[107] Luciano Pezzano, "La responsabilidad de proteger cumple quince años: ¿celebración o despedida?", Universidad Nacional de La Plata, 2016, pp. 11-12, en sedici.unlp.edu.ar/handle/10915/58247, fecha de consulta: 25 de junio de 2019.

[108] Laurence Boisson de Chazournes y Luigi Condorelli, "De la 'responsabilité de protéger', ou d'une nouvelle parure pour une notion déjà bien établie", Revue générale de droit international public 1 (2006), pp. 11-18.

\section{Bibliografía}

Ambos, Kai, Nociones básicas del derecho internacional humanitario, Valencia, Tirant lo Blanch, 2011.

Arredondo, Ricardo, Intervención humanitaria y Responsabilidad de Proteger. ¿Hacia un nuevo paradigma de protección de los derechos humanos?, Buenos Aires, Catálogos, 2012.

Asamblea General, Acta literal de la 93ª sesión plenaria, un.Doc.A/73/PV.93, Nueva York, Naciones Unidas, 2019.

Asamblea General, Documento Final de la Cumbre Mundial 2005,Resolución 60/1, Nueva York, Naciones Unidas, 2005. 
Ban, Ki-moon, "La responsabilidad de proteger: respuesta oportuna y decisiva. Informe del Secretario General”, un.Doc.A/66/874-S/2012/578, Nueva York, Naciones Unidas, 2012.

Ban, Ki-moon, "La responsabilidad de proteger: responsabilidad del Estado y prevención. Informe del Secretario General”, un.Doc.A/67/929-S/2013/399, Nueva York, Naciones Unidas, 2013.

Ban, Ki-moon, "Cumplimiento de nuestra responsabilidad colectiva: asistencia internacional y la responsabilidad de proteger. Informe del Secretario General”, un.Doc.A/68/947-S/2014/449, Nueva York, Naciones Unidas, 2014.

Ban, Ki-moon, "Hacer efectiva la responsabilidad de proteger. Informe del Secretario General", un.Doc.A/63/677, Nueva York, Naciones Unidas, 2009.

Bellamy, Alex J., "Making RTOP a living reality: Reflections on the 2012 General Assembly dialogue on timely and decisive response", Global Responsibility to Protect 5 (2013), pp. 109-125.

Boisson De Chazournes, Laurence y Luigi Condorelli, "De la 'responsabilité de protéger', ou d'une nouvelle parure pour une notion déjà bien établie", Revue générale de droit international public 1 (2006), pp. 11-18.

Breakey, Hugh, "Protection norms and human rights: A rights-based analysis of the responsibility to protect and the protection of civilians in armed conflict", Global Responsibility to Protect 4 (2012), pp. 309-333.

Bugnion, François, "Just wars, wars of aggression and international humanitarian law", International Review of the Red Cross 849 (2003), pp. 3-26.

CDI, "Normas imperativas de derecho internacional general (ius cogens)". Texto del proyecto de conclusiones y del proyecto de anexo aprobados provisionalmente por el Comité de Redacción en primera lectura, un.Doc.A/CN.4/L.936, Ginebra, Naciones Unidas, 2019.

CICR, Commentary on the First Geneva Convention: Convention (I) for the Amelioration of the Condition of the Wounded and Sick in Armed Forces in the Field, 2nd edition, 2016, en ihl-databases.icrc.org/ihl/full/GCl-commentary., fecha de consulta: 14 de junio de 2019.

CIJ, "Legal consequences of the construction of a wall in the occupied palestinian territory", Advisory Opinion, ICJ Reports 2004, p. 136.

CIJ, "Legality of the threat or use of nuclear weapons", Advisory Opinion, ICJ Reports 1996, p. 226.

ClJ, Military and paramilitary activities in and against Nicaragua (Nicaragua v. United States of America). Merits, Judgment. ICJ Reports 1986.

Comellas Aguirrezábal, María Teresa, La incidencia de la práctica del Consejo de Seguridad en el Derecho Internacional Humanitario, Pamplona, Thomson-Aranzadi, 2007.

Comisión Internacional Sobre Intervención y Soberanía de los Estados, La responsabilidad de proteger, Informe de la Comisión Internacional sobre Intervención y soberanía de los Estados, Ottawa, 2001.

De Wet, Erika, The Chapter VII Powers of the United Nations Security Council, Oxford, Hart Publishing, 2004

Francis, Angus, Vesselin Popovski y Charles Sampford, Norms of protection: Responsibility to protect, protection of civilians and their interaction, Tokio, United Nations University Press, 2013, 
García Martin, Isabel, "El principio de la responsabilidad de proteger: ¿supone una nueva excepción al uso de la fuerza?" Revista Enfoques: Ciencia Política y Administración Pública XV, 27 (2017), pp. 173-193

Gasser, Hans-Peter y Knut Dörmann, "Protection of the civilian population”, en Dieter Fleck (ed.), The Handbook of International Humanitarian Law, 3 ed., Oxford, Oxford University Press, 2013.

Greenwood, Christopher, "International humanitarian law and united nations military operations", Yearbook of International Humanitarian Law 1 (1998), pp. 3-34.

Grupo de alto nivel, "Un mundo más seguro: la responsabilidad que compartimos. Informe del Grupo de Alto Nivel sobre las amenazas, los desafíos y el cambio. Nota del Secretario General”, un.Doc.A/59/565, Nueva York, Naciones Unidas, 2004.

Guterres, Antônio, "La aplicación de la responsabilidad de proteger: la rendición de cuentas en materia de prevención. Informe del Secretario General”, un.Doc.A/71/1016-S/2017/556, Nueva York, Naciones Unidas, 2017.

Gutiérrez Posse, Hortensia, Elementos de derecho internacional humanitario, Buenos Aires, Eudeba, 2014.

Henckaerts, Jean-Marie y Louise Doswald-Beck, El derecho internacional humanitario consuetudinario, Ginebra, Comité Internacional de la Cruz Roja, 2007.

Kolb, Andreas S., The un Security Council Members' Responsibility to Protect. A Legal Analysis, Berlin, Springer, 2018.

Krisch, Nico, "Article 39", en Bruno Simma et al. (eds.), The Charter of the United Nations: A Commentary, vol. II, 3 ed., Oxford, Oxford University Press, 2012, pp. 1278-1293.

Naciones Unidas, "Carta de fecha 9 de noviembre de 2011, dirigida al Secretario General por la Representante Permanente de Brasil ante las Naciones Unidas", un.Doc.A/66/551-S/2011/701, Nueva York, Naciones Unidas, 2011.

Okimoto, Keiichiro, "Violations of international humanitarian law by United Nations forces and their legal consequences", Yearbook of International Humanitarian Law 6 (2003), pp 199-236.

Pezzano, Luciano, "Los Movimientos de Liberación Nacional en el pensamiento de Julio A. Barberis", Cuadernos de Derecho Internacional IX (2015), pp. 211-242

Pezzano, Luciano, La responsabilidad de proteger cumple quince años: ¿celebración o despedida?, en http://sedici.unlp.edu.ar/handle/10915/58247, fecha de consulta: 25 de junio de 2019.

Pezzano, Luciano, La Responsabilidad de Proteger en las Naciones Unidas, Córdoba, Centro de Estudios AvanzadosAdvocatus, 2016.

Pictet, Jean (dir.), Commentary on the Geneva Convention relative to the protection of civilian persons in time of war, Ginebra, cicr, 1958.

Roscini, Marco, "The United Nations Security Council and the enforcement of international humanitarian law", Israel Law Review 43, 2 (2010), pp. 330-359.

Rosenberg, Sheri P. y Ekkehard Strauss, "A Common Standard for Applying r2p", Cardozo Law 2013, en www.globalr2p.org/media/files/r2p_standards_policy_letter-1.pdf, fecha de consulta: 25 de junio de 2019. 
Sandoz, Yves, Christophe Swinarski y Bruno Zimmermann, Commentary on the Additional Protocols of 8 June 1977 to the Geneva Conventions of 12 August 1949, Ginebra, Comité Internacional de la Cruz Roja, 1987.

Secretario General, "Observance by United Nations forces of international humanitarian law”, un.Doc.st/sgb/1999/13, Nueva York, Naciones Unidas, 1999.

TPIY, Prosecutor v. Duško Tadić a.k.a. "Dule". Decision on the Defence Motion for Interlocutory Appeal on Jurisdiction, 2 de octubre de 1995.

TPIY, Prosecutor v. Kupreskic et al.Decision on evidence of the good character of the accused and the defence of tu quoque, 17 de febrero de 1999.

Welsh, Jennifer, "Implementing the 'responsibility to protect”, Policy Brief 1 (2009).

Wills, Siobhán, Protecting Civilians, Oxford University Press, 2009.

Universidad de La Sabana.

Código SNIES 1711

Personería Jurídica: Resolución 130 del 14 de enero de 1980. Ministerio de Educación Nacional.

Carácter académico: universidad.

Síguenos en nuestras redes

You

Tulbe

Comunícate con nosotros

Unidades Académicas

CESU

Política de Protección de datos

Contacto para notificaciones legales

Si tiene alguna notificación legal puede enviarla al correo: notificacioneslegales@unisabana.edu.co

Institución de educación superior sujeta a inspección y vigilancia por el Ministerio de Educación Nacional.

Copyright 2017. Universidad de La Sabana. Todos los derechos reservados.

Campus del Puente del Común, Km. 7, Autopista Norte de Bogotá. Chía, Cundinamarca, Colombia.

Contact Center: 8615555 / 861 6666. Apartado: 53753, Bogotá. 
